\title{
Practical Breeding of Red-fleshed Apple: Cultivar Combination for Efficient Red-fleshed Progeny Production
}

\author{
Hitomi Umemura, Katsuhiro Shiratake, and Shogo Matsumoto ${ }^{1}$ \\ Graduate School of Bioagricultural Sciences, Nagoya University, Chikusa, \\ Nagoya 464-8601, Japan
}

\section{Tsutomu Maejima and Hiromitsu Komatsu \\ Nagano Fruit Tree Experiment Station, Nagano 382-0072, Japan}

Additional index words. Malus $\times$ domestica, red flesh color, $S_{3}$-RNase allele, $S_{11}$-RNase allele

Abstract. We re-investigated the flesh color and $S$-genotypes of progenies of red-fleshed apple cultivar JPP35, which was produced by 'Jonathan' $\times$ 'Pink Pearl', and clarified that $100 \%$ and $96 \%$ of progenies from 'Shinano Sweet' $\left(S_{1} S_{7}\right) \times$ 'JPP35' $\left(S_{3} S_{7}\right)$ and 'Orin' $\left(S_{2} S_{7}\right) \times$ 'JPP35' $\left(S_{3} S_{7}\right)$ containing $S_{3}$-RNase allele, respectively, showed the red flesh trait. Using this tight linkage between red flesh trait and self- and cross-compatibility relating allele such as $S_{3}$-RNase allele, we showed suitable cultivar combinations for efficient production of various red-fleshed apples. We also identified an unknown $S$-RNase allele in 'Pink Pearl' as $S_{11}$ and determined its partial genomic sequence, including a complete intron with its known $S_{3}$-RNase allele.

Variation of flesh color in apple (Malus $\times$ domestica Borkh.) such as white or yellowish white is less than that of skin color with various shades of red, yellow, and green. Recently, the red-fleshed apple has attracted attention for its novel color, and new cultivars, Weirouge, Redlove Era, and Redlove Sirena, are planned for release within a few years (Warner, 2010). Red-fleshed cultivars are expected to have physiological functions such as antioxidative activity that were observed in the red skin cultivars (Eberhardt et al., 2000; Wolfe et al., 2003). One of the anthocyanins, cyanidin 3-galactoside, is mainly responsible for apple red coloration, and R2R3-MYB transcription factors have been shown to play an important role in transcriptional regulation of enzymes in the anthocyanin biosynthetic pathway of apple (Allan et al., 2007; Tsao et al., 2003). To date, two $M d M Y B$ alleles, $M d M Y B 1$ and 10, which are responsible for apple skin and flesh color, respectively, have been identified (Ban et al., 2007; Chagné et al., 2007; Espley et al., 2007; Takos et al., 2006). Espley et al. (2009) found that the modification of the MdMYB10 upstream region, i.e., five direct tandem repeats

Received for publication 25 Mar. 2011. Accepted for publication 6 June 2011 .

This research was supported by a Grant-in-Aid for Scientific Research from the Japan Society for the Promotion of Science, the Research Project for Utilizing Advanced Technologies in Agriculture, Forestry and Fisheries, and the Towa Foundation for Food Research.

We thank Ms. Keiko Sekido for her technical assistance.

${ }^{1}$ To whom reprint requests should be addressed; e-mailshogo@agr.nagoya-u.ac.jp. of a 23-bp sequence in the promoter region (the R6 promoter) in red-fleshed apples, was not present in white-fleshed apples (no tandem repeats, the $\mathrm{R} 1$ promoter). They showed the repeat number of the 23-bp sequence correlated to a mechanism for upregulation of the anthocyanin pathway leading to red flesh through the autoregulation of the R6 promoter by $M d M Y B 10$.

Recently, we found that the R6 promoter was not observed at the promoter region of $M d M Y B$ in red-fleshed apple cultivars Pink Pearl ('Surprise' $\times$ unknown pollen parent, selected in 1944), JPP35 ('Jonathan' $\times$ 'Pink Pearl'), and any of their progenies with the red flesh trait (Sekido et al., 2010a). Although the molecular mechanism of their red coloration is largely unknown, we indicated that the red flesh trait in 'Pink Pearl' is tightly linked with its $S_{3}$-RNase allele (Sekido et al., 2010a). Because the flesh and skin color trait within the Rni locus (the site of MdMYB 1 and 10) located in linkage group 9, not 17 of the $S$-allele location, and which is called the $S$-locus (Chagné et al., 2007; Maliepaard et al., 1998), the red flesh trait in 'Pink Pearl' seemed to be controlled by a different type of MYB transcription factor close to the $S_{3}$ RNase allele. Self-incompatibility in apple is gametophytically controlled by the $S$-locus and not only self pollen-tube growth, but also pollen tube growth from a different cultivar having the same $S$-haplotype can be arrested in the style (de Nettancourt, 1977; Kobel et al., 1939). For instance, 'Shinano Sweet' $\left(S_{1} S_{7}\right) \times$ 'JPP35' $\left(S_{3} S_{7}\right)$ results in either $S_{1} S_{3}$ or $S_{3} S_{7}$ progenies because the $S_{7}$-allele in 'JPP35' is rejected by that in 'Shinano Sweet'. The $S$-RNase and SFB ( $S$-locus F-box) genes, which are functional in pistils and pollen, respectively, are located within the $S$-locus (Broothaerts et al., 1995; Cheng et al., 2006), and from the nucleotide sequences of the $S$-RNases, the polymerase chain reaction (PCR)-based $S$-RNase allele genotype analysis method was developed (Broothaerts, 2003; Kim et al., 2009; Kitahara and Matsumoto, 2002a, 2002b; Matsumoto and Kitahara, 2000; Matsumoto et al., 2009a; Morita et al., 2009). Using the PCR method, we have investigated the $S$-RNase content of more than 500 apple cultivars, lineages, and species in Japan (Kitahara and Matsumoto, 2002a, 2002b; Kitahara et al., 1999, 2000; Matsumoto and Kitahara, 2000; Matsumoto et al., 1999a, 1999b, 2001, 2003a, 2003b, 2003c, 2007, 2009b; unpublished results).

In this article, we show a strategy for efficient production of red-fleshed apple progenies. This will be useful for producing new red-fleshed cultivars because the genetic background of the red flesh trait in 'Pink Pearl' is quite different from that of cultivars to be released in the near future.

\section{Materials and Methods}

Plant material. Malus plants used in this study were from collections at the Nagano Fruit Tree Experiment Station, Japan. Young leaves were collected and stored at $-80{ }^{\circ} \mathrm{C}$ until use.

Measurement of anthocyanin in apple. Ten to 20 fruits of 'JPP35', 'Maypole', and 'Fuji' were picked monthly from May to October. Half of the fruit on the tree was placed in light-impermeable two-layered double bags (Kobayashi Bag Mfg., Nagano, Japan) after $\approx 1$ ('Maypole') or 2 ('JPP35' and 'Fuji') months of full bloom. The twolayered double bag blocks $99.6 \%$ to $99.7 \%$ of light corresponding to a wavelength range of $200 \mathrm{~nm}$ to $1100 \mathrm{~nm}$. Anthocyanin measurement has been done essentially according to the method of Dong et al. (1995). A 1.0-g core or cortex of apple fruit was freeze-dried for $24 \mathrm{~h}$, total anthocyanins were extracted overnight with $1 \% \mathrm{HCl}$-methanol $(5 \mathrm{~mL})$, and the absorbance of the extracts were measured at $530 \mathrm{~nm}$ and $657 \mathrm{~nm}$. The difference between $\mathrm{A}_{530}$ and $\mathrm{A}_{657}$ was used to determine the concentration of total anthocyanin and eliminate the contribution of chlorophyll and its degradation products. Measurements were repeated three times, and the average value (mean $\pm \mathrm{SD}$ ) is plotted in Figure 1.

$S$-RNase allele-specific polymerase chain reaction-digestion analysis. Total DNA from the leaves of individual plants was isolated as described by Thomas et al. (1993). The primers and conditions used for the $S$-RNase allele-specific PCR amplification and digestion were essentially those described by Broothaerts (2003) $\left(S_{2^{-}}, S_{3^{-}}\right.$and $S_{7}$-RNase allele), Kitahara and Matsumoto (2002b) ( $S_{3^{-}}$and $S_{10^{-}}$RNase allele), Matsumoto et al. (1999a) $\left(S_{7}\right.$-RNase allele), and Matsumoto et al. (1999b) $\left(S_{1^{-}}\right.$ RNase allele).

Sequence analysis of $S_{3^{-}}$and $S_{11}$-RNase alleles. The ca 1500-bp and 370-bp fragments were amplified from 'Pink Pearl' 
genomic DNA using the sense ('FTQQYQ') and antisense ('anti- $1 / \mathrm{M} I W P N V$ ') primers (Matsumoto and Kitahara, 2000). The reaction to DNA amplification was conducted in a $20-\mu \mathrm{L}$ mixture containing $50 \mathrm{ng}$ of genomic DNA, $200 \mu \mathrm{M}$ of each deoxynucleotide, 300 $\mathrm{nM}$ of each primer, and 0.4 unit of KODPlus-DNA polymerase (TOYOBO Inc.). The analysis was programmed in a thermal Cycler (GeneAmp 2720 apparatus; Applied Biosystems) and conducted under the following conditions: 2 min preheating at $94{ }^{\circ} \mathrm{C}, 10 \mathrm{~s}$ at $98{ }^{\circ} \mathrm{C}, 30 \mathrm{~s}$ at $48{ }^{\circ} \mathrm{C}$, and $2 \mathrm{~min}$ at $68{ }^{\circ} \mathrm{C}$ for 30 cycles. The sequences of the amplified fragments were directly determined by performing dideoxy chain termination on an Applied Biosystems 3130 Genetic Analyzer (Life Technologies Japan Co., Ltd.) using a Big Dye Terminator Version 3.1 Cycle Sequencing Kit (Life Technologies Japan Co., Ltd.).

\section{Results and Discussion}

Accurate linkage between red flesh trait and $S_{3}$-RNase in 'Pink Pearl'. Previously, we indicated that 67 of $70(96 \%)$ and 51 of $58(88 \%)$ progenies from 'Shinano Sweet' $\left(S_{1} S_{7}\right) \times$ 'JPP 35' $\left(S_{3} S_{7}\right)$ and 'Orin' $\left(S_{2} S_{7}\right) \times$ 'JPP 35' $\left(S_{3} S_{7}\right)$, respectively, showed the red flesh color because the $S_{3}$-RNase allele of 'Pink Pearl' was linked to its red flesh trait (Sekido et al., 2010a). At that time, we proposed that some progenies with white flesh color would turn white-pink after full maturity. As shown in Figure 1, red pigmentation in 'JPP35' flesh cortex increased according to fruit maturity in contrast to the cultivar Maypole in which red skin, flesh, and leaf color might be controlled by the MdMYB10 (Sekido et al., 2010b). The red pigmentation in the cortex of 'Maypole' decreased according to fruit maturity (Fig. 1). Moreover, the red pigmentation of the flesh of 'JPP35' progressed without ultraviolet rays, which are essential for the development of red skin color, suggesting that harvest time, not light quality, is important for development of flesh color. The white-fleshed cultivar Fuji used as a control did not change its color and no red pigmentation was observed regardless of ultraviolet irradiation (Fig. 1). We re-investigated the flesh color and $S$-genotypes of the progenies, including some additional progenies at full maturity. As shown in Table 1, all $75(100 \%)$ and 60 of $64(94 \%)$ progenies having $S_{3}$ from 'Shinano Sweet' $\left(S_{1} S_{7}\right) \times$ 'JPP $35^{\prime}\left(S_{3} S_{7}\right)$ and 'Orin' $\left(S_{2} S_{7}\right) \times$ 'JPP 35' $\left(S_{3} S_{7}\right)$, respectively, showed the red flesh color. These higher rates of red-fleshed color than previously seemed to be caused by the development of published pink-red flesh after full maturity.

Cross-combination for efficient production of red-fleshed apple progenies. We have selected 'JPP 35 ' $\left(S_{3} S_{7}\right)$ as a mother plant for production of red-fleshed cultivars (Sekido et al., 2010a). We have advanced the breeding of red-fleshed apple and selected Nos. 3, 41, and 42 as suitable for flesh use; Nos. 29, 37, 38, 44,50 , and 69 as suitable for processed goods from 'Shinano Sweet' $\left(S_{1} S_{7}\right) \times$ 'JPP 35' $\left(S_{3} S_{7}\right)$;

\section{(A)}

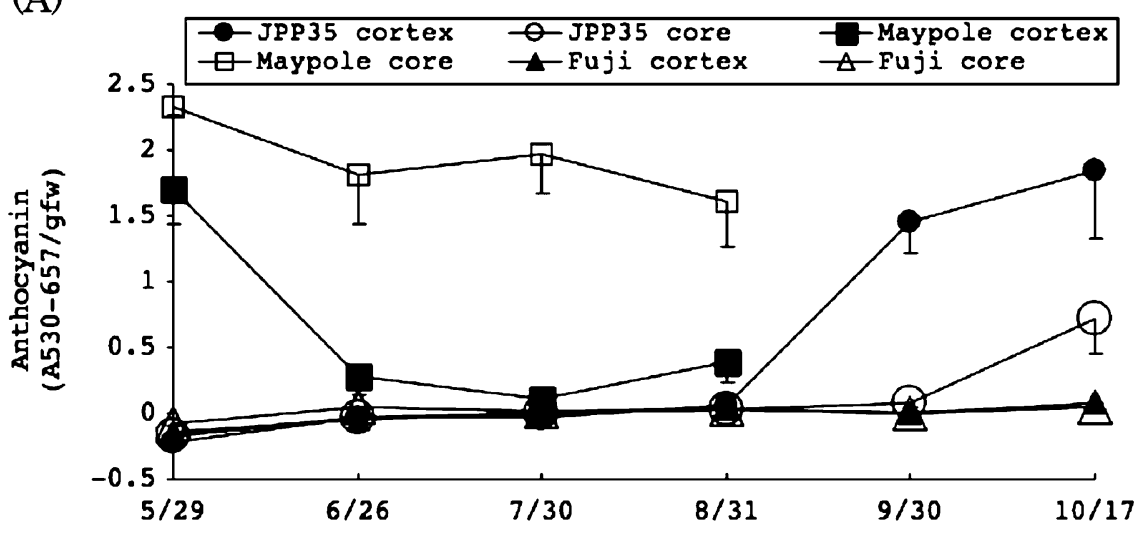

Date of harvest

(B)

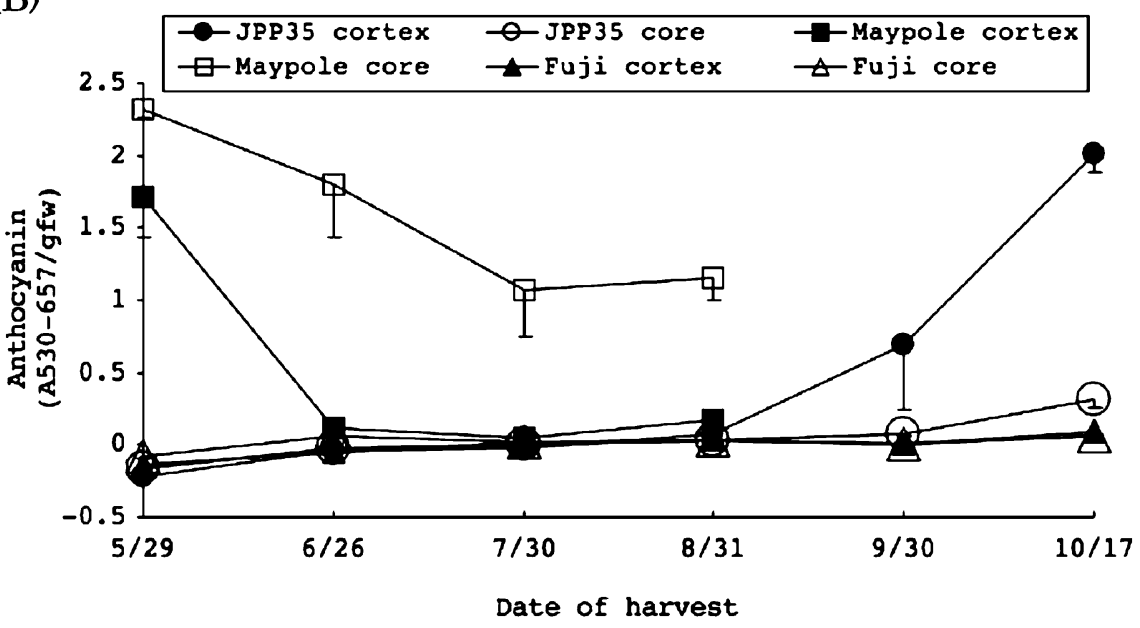

Fig. 1. Changes in the anthocyanin concentration of apple cultivars JPP35, Maypole, and Fuji core and cortex. Fruits were placed in light-impermeable two-layered 'Fuji' wrapping bags (A) and in no wrapping bags $(\mathbf{B})$.

Table 1. Rate of red-fleshed progenies of 'JPP35' with their $S$-RNase allele genotypes.

\begin{tabular}{|c|c|c|c|c|c|}
\hline \multirow[b]{2}{*}{ Cross } & \multirow[b]{2}{*}{ Yr } & \multicolumn{2}{|c|}{ Flesh color ( $S$-genotype) } & \multicolumn{2}{|c|}{ Rate of red flesh $(\%)$} \\
\hline & & Red & White & Expected & Observed \\
\hline Shinano Sweet $\left(S_{1} S_{7}\right)$ & $2009^{z}$ & $67\left(30 S_{1} S_{3} 37 S_{3} S_{7}\right)$ & $3\left(S_{3} S_{7}\right)$ & 100 & 96 \\
\hline$\times \operatorname{JPP} 35\left(S_{3} S_{7}\right)$ & 2010 & $75\left(35 S_{1} S_{3} 40 S_{3} S_{7}\right)$ & 0 & 100 & 100 \\
\hline Orin $\left(S_{2} S_{7}\right)$ & $2009^{z}$ & $51\left(28 S_{2} S_{3} 23 S_{3} S_{7}\right)$ & $8\left(5 S_{2} S_{3} 3 S_{3} S_{7}\right)$ & 100 & 86 \\
\hline$\times \mathrm{JPP} 35\left(S_{3} S_{7}\right)$ & 2010 & $60\left(35 S_{2} S_{3} 25 S_{3} S_{7}\right)$ & $4\left(2 S_{2} S_{3} 2 S_{3} S_{7}\right)$ & 100 & 94 \\
\hline Pink Pearl $\left(S_{3} S_{11}\right)$ & $2009^{z}$ & $13\left(12 S_{3} S_{7} 1 S_{7} S_{11}\right)$ & $17\left(17 S_{7} S_{11}\right)$ & 50 & 43 \\
\hline$\times$ JPP $35\left(S_{3} S_{7}\right)$ & 2010 & $13\left(12 S_{3} S_{7} 1 S_{7} S_{11}^{\mathrm{y}}\right)$ & $19\left(19 S_{7} S_{11}\right)$ & 50 & 41 \\
\hline
\end{tabular}

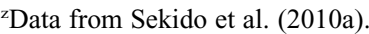

${ }^{\mathrm{y}}$ The progeny was classified as No. 25 .

and confirmed their $S$-RNase genotypes (Table $2)$. From the $S$-genotypes, new red-fleshed cultivars having variable taste and texture could be obtained efficiently by crossing $S_{3} S_{7}$ genotypes of 'JPP 35', Nos. 3, 42, 37, 50, and 69 with $S_{3}$-absence and $S_{7}$-presence cultivars such as 'Jonathan' $\left(S_{7} S_{9}\right)$, 'Shinano Sweet' $\left(S_{1} S_{7}\right)$, 'Orin' $\left(S_{2} S_{7}\right)$, etc. Also, in the case of $S_{I} S_{3}$ genotypes of Nos. 41, 29, 38, and 44, $S_{3}$-absence and $S_{1}$-presence cultivars such as 'Fuji' $\left(S_{I} S_{9}\right)$, 'Ralls Janet' $\left(S_{l} S_{2}\right)$, and 'Senshu' $\left(S_{1} S_{7}\right)$ could be used as a cross hybridization partner for efficient production of new redfleshed apples. In this case, new red-fleshed cultivars incorporating characteristics of the major cultivar Fuji $\left(S_{I} S_{9}\right)$ will be obtained efficiently.
Table 2. S-RNase allele genotypes of 'Shinano Sweet' $\times$ 'JPP35' progenies.

\begin{tabular}{lllc}
\hline Lineage & Fresh color & Suitable for & $S$-genotype \\
\hline No. 3 & Pink-red & Fresh use & $S_{3} S_{7}$ \\
No. 41 & Red & Fresh use & $S_{1} S_{3}$ \\
No. 42 & Pink-red & Fresh use & $S_{3} S_{7}$ \\
No. 29 & Red & Processing & $S_{1} S_{3}$ \\
No. 37 & Pink-red & Processing & $S_{3} S_{7}$ \\
No. 38 & Red & Processing & $S_{1} S_{3}$ \\
No. 44 & Red & Processing & $S_{1} S_{3}$ \\
No. 50 & Red & Processing & $S_{3} S_{7}$ \\
No. 69 & Red & Processing & $S_{3} S_{7}$ \\
\hline
\end{tabular}

Molecular structure of $S_{3}$ - and $S_{11}$-RNase allele in 'Pink Pearl'. Only one progeny, No. $25\left(S_{7} S_{x} ; S_{x}\right.$ is unknown $S$-RNase allele) from 'Pink Pearl' $\left(S_{3} S_{x}\right) \times$ 'JPP 35' $\left(S_{3} S_{7}\right)$, showed 
the red-fleshed trait despite its absence of $S_{3}$ (Table 1). In this case, the gene responsible for the red-fleshed trait seems to be present near the $S_{7^{-}}$or $S_{x}$-RNase allele by genetic recombination. To clarify the $S_{x}$-RNase allele structure, we investigated the $S$-RNase allele in 'Pink Pearl' using primers 'FTQQYQ' and 'anti-1/MIWPNV'. It was clarified that 'Pink Pearl' had $S_{11}$-RNase allele in addition to the known $S_{3}$-RNase allele (Fig. 2). The partial coding sequences with deduced intron sequences of $S_{11}$-RNase allele in 'Pink Pearl' were completely identical with those in 'Gravenstein' and 'Virginia crab' (Long et al., 2010; Matsumoto et al., 2003c). In contrast, we found a nucleotide substitution between the intron sequences of $S_{3}$-RNase allele in 'Pink Pearl' and 'Mutsu' at position 343 (Fig. 2). We thought the polymorphism might be useful to discriminate the 'Pink Pearl' $S_{3}$-RNase allele with commercial cultivars in Japan having the $S_{3}$-RNase allele. However, the polymorphism seems ambiguous because we could not identify the polymorphism in our 'Mutsu' $\left(S_{2} S_{3} S_{20}\right)$, 'Golden Delicious' $\left(S_{2} S_{3}\right)$, and 'Shinano Gold' $\left(S_{1} S_{3}\right)$ samples. We have obtained a 124-bp fragment corresponding to the 'Pink Pearl' $S_{3}$ from the cultivars using the primers S3PF $\left(5^{\prime}\right.$-TCCTAACTAATTTT CAATTC-3'; position 324-343 in Fig. 2) and S3PR (5'-GGATTATATGAATGGCTACAT TTAAGA-3'; position $421-447$ in Fig. 2) (results not shown). Although we could not discriminate the $S_{3}$ of 'Pink Pearl' from those of commercial cultivars using the identified single nucleotide polymorphism, we used the primers to confirm the absence of $S_{3}$ in a newly arrived red-fleshed material from ['Hatsushiga' $\left.\left(S_{2} S_{9}\right) \times 4-23\left(S_{1} S_{2}\right)\right] \times$ 'Megumi' $\left(S_{2} S_{9}\right)$. Contrary to expectations, $S_{3}$ seemed to be present

(A)

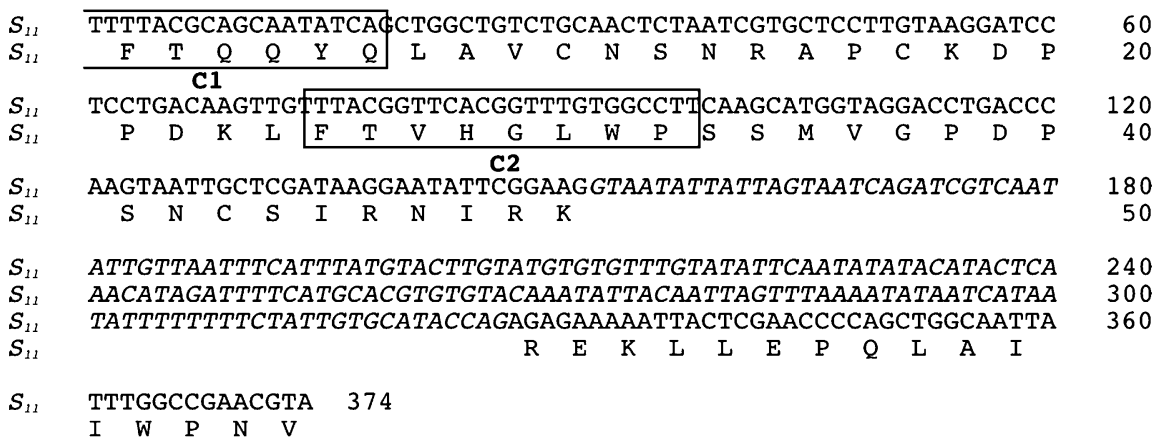

(B)

$S_{3 p}$ AGGATCCTCCTGACAAGTTG TTACGGTTCATGGTTTGTGGCTTCAAATGTTAATGGAA

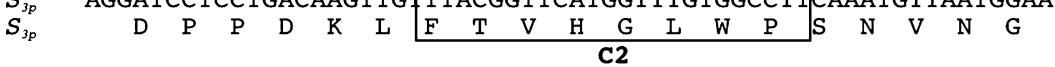
\begin{tabular}{lllllllllllllllll}
$S_{3 p}$ & \multicolumn{1}{c}{ GTGACCCCAAGAAATGAAACTACAATCTTGACCCAAACGTAATATTATTCAGGC } \\
$S_{3 p}$ & $\mathrm{~S}$ & $\mathrm{D}$ & $\mathrm{P}$ & $\mathrm{K}$ & $\mathrm{K}$ & $\mathrm{C}$ & $\mathrm{K}$ & $\mathrm{T}$ & $\mathrm{T}$ & $\mathrm{I}$ & $\mathrm{L}$ & $\mathrm{N}$ & $\mathrm{P}$ & $\mathrm{Q}$ & $\mathrm{T}$
\end{tabular}

$S_{3 p}$ AAAATTAATATCCAGTACTTAGTTATAATGTTCATTAATTAAGACCTTATTAGTTTTCAG $S_{3 p}$ ATTTTGATCGATGTCCCTAGCAAATTCAAATGTCAATTACATAATATTTTTAAATAAAAA $\begin{array}{ll}S_{3 p} & \text { TTAGTAATTGAAACTTACACCCTTATTAATGAATAAGTTTGTACCCATTAATTTTCAATT } \\ S_{3 p} & \text { CAAAACTTACATCCTTATTAAACTCCTAACTAATTTTCAATCAAAACATTTCCAAAAAC }\end{array}$ CAAAACTTACATCCTTATTAAACTCCTAACTAATTTTCAATTCA TAAAAATTAGAATAAGTTTGTACCCATTAATTTTTTATAAAATGATTTTCAATTTTTTAA TCTTAAATGTAGCCATTCATATAATCCTACATTTACCCATTCTTAAATATACCATTTTGT S3PR

TATGTAAAATGTACCCTTTTTAAAATATAAATGTAACCCTTGTTTATATAAAATACATTC AATTTTTTTTTTCTAAACCATATATTTTAAATTATCCATTTTTAATATAAAACGTAACCA TTTTTTATATTAAATCAATTCAAATTTTTTTTTCGAATCCATTTTTTAAACTTATATGGG TACATTCTATTTCGTTGATTTGAGAGTCTATCGATACCAAGTTTAATGGAAGAATTTAA TAATGTAAGCCTAATACCTCTTTTTTTTCTTTCAAAAATCTACCTATGTTTGATACAATA ATTTTTTGTTAGTTTTAATGAACGTACCCATGTTTTCTTATATATATATATATATATATG CATGCATGTATGTATGTATATATATATATAACATATTGGAGGGCATAAAAAGGTCGTACC CAGTGCACAAGGCTCCCGCTTTACGCAGGGTCTGGGAGAAGTGAATGTCGGCTAGCCTTA CCCCCATTTATGGAGAGGCTGCTCCCAAGTCTCGAACCCGAGACCTACCGCTCATGGGCG AAGGCACTTGCCATAATTTACTTTAAATTTTTTAATCCTATAAATGGATTTTATTTAAAA TCTCATTGATATAAACAACCATAAATTTTAATTTTTCATTTAAAATTATAATAATCTACA TAAAAATACATTATTATATTAATGTCAGAAACTTTGATCAAAAACTGAAAATGAGTAAGA TTTCAATTAAAGAACATTGATTATTAGTACTGTGTCCAAAATCTCCCTATTATTCATAAT TAGATGGTCAAATTGTTTATCTTTTCATATATACACATGCTCGACATAGATTTTCATGCA CTCGTGAAAGATATTACTATTAATTTAAAATTTAATCATAATTTTTTTTTTCTATTATAA TATTGTAT-GTCAGATAACA 1399 $T$

$$
\text { I } \quad \begin{array}{r}
1400 \\
36
\end{array}
$$

Fig. 2. Partial nucleotide and deduced amino acid sequences of $S_{11^{-}}(\mathbf{A})$ and $S_{3^{-}}$RNase alleles in 'Pink Pearl' (B). The conserved regions $\mathrm{C} 1$ and $\mathrm{C} 2$ are boxed. The deduced intron sequences are italicized. Sequences of $S_{11}$ and $S_{3}$ from 'Pink Pearl' were deposited under the DDBJ accession numbers $\mathrm{AB} 618093$ and AB618094, respectively. The nucleotide sequence of $S_{11}$-RNase allele in 'Pink Pearl' was completely identical with that in 'Gravenstein' (AB105060) and 'Virginia crab' (FJ008669). In the case of the $S_{3}$-RNase allele, a nucleotide substitution at position 343 from C ( $S_{3 p} ; S_{3}$ in 'Pink Pearl') to $\mathrm{T}\left(S_{3 m} ; S_{3}\right.$ in 'Mutsu' from AB428425) and an insertion of T at position 1389 of $S_{3 m}$ were identified. Sequences used as primers to identify the $S_{3}$ (S3PF and S3PR) are underlined. in the material because we were able to detect a 124-bp fragment (results not shown). Because 'JPP35' alone was a red-fleshed cultivar having $S_{3}$ within pollen parents in use, the material seemed to be produced by 'JPP35' pollen accidentally used somewhere in the breeding process.

Using the No. $25\left(S_{7} S_{11}\right)$, it is possible to produce new red-flesh cultivars that are homozygous for the red flesh allele derived from 'Pink Pearl', which we considered useful for producing stable dark red-fleshed cultivars. Thus, either $S_{3} S_{7}$ or $S_{3} S_{11}$ from 'Pink Pearl' $\left(S_{3} S_{11}\right) \times$ No. $25\left(S_{7} S_{11}\right)$ or 'JPP 35 ' $\left(S_{3} S_{7}\right) \times$ No. $25\left(S_{7} S_{11}\right)$, respectively, must be homozygous with the red flesh trait. In addition, if the red flesh trait in No. 25 is linked to the $S_{11}$, we can use a $S_{3}$ cultivar such as the major cultivar Tsugaru $\left(S_{3} S_{7}\right)$ as a partner for the crossing of No. $25\left(S_{7} S_{11}\right)$. $S$-genotypes of $\mathrm{F}_{1}$ from 'Tsugaru' $\left(S_{3} S_{7}\right) \times$ No. $25\left(S_{7} S_{11}\right)$ will be either $S_{3} S_{11}$ or $S_{7} S_{11}$ and must show the red flesh trait because all the $\mathrm{F}_{1}$ have $S_{11}$.

In conclusion, breeding for new redfleshed apple cultivars using the linkage between the red flesh trait and the $S$-allele is a genuine breakthrough not only for its contribution to efficient red-fleshed apple breeding, but also for its expansion of the breeding range. For instance, yellow skin and the redfleshed cultivar could be obtained from the progenies of 'Orin' (yellow skin and white flesh) and 'JPP35' (red skin and flesh), a combination not possible from the progenies with the $M d M Y B 10$ allele because the fruit skin and leaves are also controlled by the MdMYB10.

\section{Literature Cited}

60

120

34

180

240

300

360
360

420

480

540

600

660

720
780

840

900

960

1020

1080
1140

1200

1260

1320

1380

80

C

de Nettancourt, D. 1977. Incompatibility in angiosperms, p. 28-57. In: Frankel, R., G.A.E. Gal, and H.F. Linskens (eds.). Monographs on theoretical and applied genetics. Springer-Verlag, Heidelberg, Germany.

Dong, Y.-h., D. Mitra, and A. Kootstra. 1995. Postharvest stimulation of skin color in Royal Gala apple. J. Amer. Soc. Hort. Sci. 120:95-100. MYB transcription factors that colour our fruit. Trends Plant Sci. 13:99-102.

Ban, Y., C. Honda, Y. Hatsuyama, M. Igarashi, H. Bessho, and T. Moriguchi. 2007. Isolation and functional analysis of a MYB transcription factor gene that is a key regulator for the development of red coloration in apple skin. Plant Cell Physiol. 48:958-970.

Broothaerts, W. 2003. New findings in apple Sgenotype analysis resolve previous confusion and request the re-numbering of some S-alleles. Theor. Appl. Genet. 106:703-714.

Broothaerts, W., G.A. Janssens, P. Proost, and W.F. Broekaert. 1995. cDNA cloning and molecular analysis of two self-incompatibility alleles from apple. Plant Mol. Biol. 27:499-511.

Chagné, D., C.M. Carlisle, C. Blond, R.K. Volz, C.J. Whitworth, N.C. Oraguzie, R.N. Crowhurst, A.C. Allan, R.V. Espley, R.P. Hellens, and S.E. Gardiner. 2007. Mapping a candidate gene (MdMYB10) for red flesh and foliage colour apple. BMC Genomics 8:212.

heng, J., Z. Han, X. Xu, and T. Li. 2006. Isolation and identification of the pollen-expressed polymorphic F-box genes linked to the $S$-locus in HortScience Vol. 46(8) August 2011 
Eberhardt, M.V., C.Y. Lee, and R.H. Liu. 2000. Antioxidant activity of fresh apples. Nature 405:903-904.

Espley, R.V., C. Brendolise, D. Changé, S. KuttyAmma, S. Green, R. Volz, J. Putterill, H.J. Schouten, S.E. Gardiner, R.P. Hellens, and A.C. Allan. 2009. Multiple repeats of a promoter segment causes transcription factor autoregulation in red apples. Plant Cell 21:168-183.

Espley, R.V., R.P. Hellens, J. Putterill, D.E. Stevenson, S. Kutty-Amma, and A.C. Allan. 2007. Red colouration in apple fruit is due to the activity of the MYB transcription factor, MdMYB10. Plant J. 49:414-427.

Kim, H., H. Kakui, N. Kotoda, Y. Hirata, T. Koba, and H. Sassa. 2009. Determination of partial genomic sequences and development of a CAPS system of the $S$-RNase gene for the identification of $22 S$ haplotypes of apple (Malus $\times$ domestica Borkh.). Mol. Breed. 23: 463-472.

Kitahara, K., H. Fukui, J. Soejima, and S. Matsumoto. 1999. Cloning and sequencing of a new S-gene 'Sg-RNase' (Accession NO. AB019184) from Malus $\times$ domestica Borkh. 'Indo' (PGR99-046). Plant Physiol. 119:1567.

Kitahara, K., J. Soejima, H. Komatsu, H. Fukui, and S. Matsumoto. 2000. Complete sequences of the S-genes, Sd- and Sh-RNase cDNA in apple. HortScience 35:712-715.

Kitahara, K. and S. Matsumoto. 2002a. Cloning of the $S_{25}$ cDNA from 'McIntosh' apple and an $S_{25}$-allele identification method. J. Hort. Sci. Biotechnol. 77:724-728.

Kitahara, K. and S. Matsumoto. 2002b. Sequence of the $S_{10}$ cDNA from 'McIntosh' apple and a PCR-digestion identification method. HortScience 37:187-190.

Kobel, F., P. Steinegger, and J. Anliker. 1939. Weitere Untersuchungen über die Befruchtungsverhältnisse der Apfel- und Birnsorten. Landw Jahrb. Schweiz. 53:160-191.

Long, S., M. Li, Z. Han, K. Wang, and T. Li. 2010. Characterization of three new S-alleles and development of an S-allele-specific PCR system for rapidly identifying the S-genotypes in apple cultivars. Tree Genet. Genomes 6:161-168.

Maliepaard, C., F.H. Alston, G. van Arkel, L.M. Brown, E. Chevreau, F. Dunemann, K.M. Evans, S. Gardiner, P. Guilford, A.W. van Heusden, J. Janse, F. Laurens, J.R. Lynn, A.G. Manganaris, A.P.M. den Nijs, N. Periam, E. Rikkerink, P. Roche, C. Ryder, S. Sansavini, H. Schmidt, S. Tartarini, J.J. Verhaegh, M. Vrielink-van Ginkel, and G.J. King. 1998. Aligning male and female linkage maps of apple (Malus pumila Mill.) using multi-allelic markers. Theor. Appl. Genet. 97: 60-73.

Matsumoto, S., T. Eguchi, H. Bessho, and K. Abe. 2007. Determination and confirmation of $S$-RNase genotypes of apple pollinators and cultivars. J. Hort. Sci. Biotechnol. 82:323-329.

Matsumoto, S. and K. Kitahara. 2000. Discovery of a new self-incompatibility allele in apple. HortScience 35:1329-1332.

Matsumoto, S., S. Komori, K. Kitahara, S. Imazu, and J. Soejima. 1999a. S-genotypes of 15 apple cultivars and self-compatibility of 'Megumi'. J. Jpn. Soc. Hort. Sci. 68:236-241.

Matsumoto, S., K. Kitahara, S. Komori, and J. Soejima. 1999b. A new $S$-allele in apple ' $S g$ ', and its similarity to the ' $S f$ ' allele from Fuji. HortScience 34:708-710.

Matsumoto, S., K. Kitahara, H. Komatsu, and J. Soejima. 2001. A functional $S$-allele, ' $S g$ ', in the wild apple possessing a single amino acid, S-RNase 'Sg'-RNase', different from 'Sg-RNase' in Malus $\times$ domestica cultivars. J. Hort. Sci. Biotechnol. 76:163-166.

Matsumoto, S., K. Kitahara, J. Soejima, H. Komatsu, and H. Fukui. 2003a. S-allele genotype of apple cultivars and selections. Acta Hort. 622:389-396.

Matsumoto, S., Y. Furusawa, H. Komatsu, and J. Soejima. 2003b. S-allele genotypes of apple pollenizers, cultivars and linages including those resistant to scab. J. Hort. Sci. Biotechnol. 78:634-637.

Matsumoto, S., Y. Furusawa, K. Kitahara, and J. Soejima. 2003c. Partial genomic sequences of $S_{6^{-}}, S_{12^{-}}, S_{13^{-}}, S_{14^{-}}, S_{17^{-}}, S_{19^{-}}$, and $S_{21^{-}}$RNases of apple and their allele designations. Plant Biotechnol. 20:323-329.

Matsumoto, S., K. Yamada, K. Shiratake, K. Okada, and K. Abe. 2009a. Structural and functional analyses of two new S-RNase alleles, $S_{s i 5}$ and $S_{a d 5}$, in apple. J. Hort. Sci. Biotechnol. 85:131-136.

Matsumoto, S., J. Morita, K. Abe, H. Bessho, K. Yamada, K. Shiratake, and H. Fukui. 2009b. $S$-RNase genotypes of wild apples necessary for utilization as pollinizers. Hort. Environ. Biotechnol. 50:213-216.

Morita, J., K. Abe, and S. Matsumoto. 2009. SRNase genotypes of apple cultivars grown in Japan and development of a PCR-RFLP method to identify the $S_{6^{-}}$and $S_{21^{-}}$RNase alleles. J. Hort. Sci. Biotechnol. 84:29-34.

Sekido, K., Y. Hayashi, K. Yamada, K. Shiratake, T. Maejima, H. Komatsu, and S. Matsumoto. 2010a. Efficient breeding system for redfleshed apple based on linkage with $S_{3}$-RNase allele in 'Pink Pearl'. HortScience 45:534-537.

Sekido, K., K. Yamada, K. Shiratake, H. Fukui, and S. Matsumoto. 2010b. MdMYB alleles responsible for apple skin and flesh color. Curr. Top. Plant Biol. 11:17-21.

Takos, A.M., F.W. Jaffé, S.R. Jacob, J. Bogs, S.P. Robinson, and A.R. Walker. 2006. Light-induced expression of a MYB gene regulates anthocyanin biosynthesis in red apples. Plant Physiol. 142: 1216-1232.

Thomas, M., S. Matsumoto, P. Cain, and N.S. Scott. 1993. Repetitive DNA of grapevine: Class present and sequences suitable for cultivar identification. Theor. Appl. Genet. 86:173-180.

Tsao, R., R. Yang, J.C. Young, and H. Zhu. 2003. Polyphenolic profiles in eight apple cultivars using high-performance liquid chromatography (HPLC). J. Agr. Food Chem. 51:6347-6353.

Warner, G. 2010. Totally red-New apple varieties developed by Swiss breeder Markus Kobelt are red from the skin to the core. Good Fruit Grower October:20-21.

Wolfe, K., W. Wu, and R.H. Liu. 2003. Antioxidant activity of apple peels. J. Agr. Food Chem. 51:609-614. 